\title{
CHEMICAL REAGENTS FOR SELECTIVITY IN IMPROVEMENT OF RHEOLOGICAL PROPERTIES OF CRUDE OIL
}

\author{
VALI HANAQA NURULLAYEV ${ }^{* 1}$, BEYBALA TACI USUBALIYEV ${ }^{2}$, FIKRET \\ SULEYMAN GEHREMANOV ${ }^{1}$, ULKER FIKRET GEHREMANOVA ${ }^{2}$
}

\author{
${ }^{1}$ State Oil Company of the Azerbaijan Republic (SOCAR) Khodzhala Ave., Baku, Az 1025, \\ Republic of Azerbaijan \\ ${ }^{2}$ Geotechnological Problems of Oil, Gas and Chemistry, Scientific Research Institute, \\ Azerbaijan State University of Oil and Industry. Deputy Director on Science 227, D. Aliev \\ Str., Baku, Az 1010, Republic of Azerbaijan
}

\begin{abstract}
Today oil industry - one of the most developing and priority industries of Azerbaijan which plays a huge role in national economy. The need for this mineral constantly increases therefore for improvement of quality and decrease in cost of the product mining companies need to modernize constantly not only the oil-field equipment, but also to improve production processes. Now the increasing number of high-sulphurous and high-paraffinic oil fields is brought into development. As a result, the corrosion rate of the oil-field equipment increases, the output of wells decreases and expenses of mining companies in general raise.
\end{abstract}

Keywords: Physical and chemical, incompatibility, compounding, viscosity, SNPX-2005

\section{INTRODUCTION}

In recent years a considerable part of oil production is provided with inclusion in process of development of fields with heavy, high-viscosity crude oil. Production and transportation of similar to crude oil are complicated because of high viscosity and temperature of hardening, abnormal rheological behavior. The feature of these rheological properties of crude oil is shown in inconstancy of their dynamic viscosity depending on tension of shift and speed of the movement of liquid. At transport high-paraffinic the intensive parafinization of pipelines, decrease in their capacity occurs crude oil that considerably complicates operation and leads to growth of labor and material inputs. High-paraffinic oil at low temperatures show sharply expressed non-Newtonian (viscoplastic, viscoelastic, thixotropic) properties without which it is impossible to organize rational operation of wells, collecting, preparation and transport of crude oil. At a stop of process of transfer in oil paraffin structures which durability depends on the maintenance of paraffin fractions, time of rest of oil, conditions of formation of paraffin structures and other factors are formed. Renewal of process of transfer demands sometimes creation of such starting pressure which in size considerably exceed operating pressures of pipelines, fittings and the equipment.

At production and transportation of oil questions of the asphalt pitch of paraffin deposits (APPD) continue to remain relevant in spite of the fact that many various ways of their prevention and removal are already developed. Practice showed that the asphalt pitch of paraffin deposits of deposits remains the most perspective way of prevention a chemical method of impact on oil with use of additives (additives) of different function -

\footnotetext{
* Corresponding author, email: veliehet1973@mail.ru

(C) 2019 Alma Mater Publishing House
} 
depressor (reducing oil hardening temperature), inhibiting (APPD preventing emergence), etc. In oil industry use very large amount of additives, but the greatest distribution was gained by high-molecular polymeric connections of various types. It should be noted that the available additives -regulators of rheological properties of oil are not deprived of shortcomings. In some cases they show weak efficiency or have no regulating effect at all. Therefore a relevant scientific and applied task is development of new polymeric compositions for regulation of viscous and temperature properties crude oil. Sharing of several ways of impact on oil disperse systems, for example, application of various options of electric, electromagnetic, magnetic, vibration or acoustic fields is perspective. At the same time the effects corresponding to increase or, on the contrary, decrease in orderliness of supramolecular structure of substances are rather easily reached. Fight against APPD provides holding actions for two directions - to prevention of loss of deposits and their removal. An important ecological and economic task - collecting, transportation, preparation, processing and utilization of APPD and oil slimes. Further progress in area of transport and preparation problem is connected by crude oil with achievements in the field of chemistry of oil and development of new approaches to impact on oil disperse systems.

In the past Oil refinery (OR) were under construction for distillation of usual light crude oil. The current economy, changes in the price of crude oil and change of demand for distillates force OR to reduce the cost of the raw materials used by them for distillation. As a rule, it is reached by mixture of expensive light oil with heavy (non-standard) oil of poor quality, or purchase of ready mixes. Low-quality oil include heavy crude oil from the known fields and also the accidental oil supplied to the market by dealers from around the world. These grades of oil of more poor quality can be got at low price. Their mixture with expensive oil is inevitable in production of the oil mixtures having optimum properties for processing at the minimum expenses. OR around the world were under construction from such engineering positions and of such materials which allowed to carry out distillation of strictly certain types of oil. These plants were constructed on the basis of the certain types of crude oil available in their regions, the cost of certain types of oil in the market and primary demand for light distillates for production of gasoline. Distillation of crude oil, is generally directed to production of components of gasoline, such as light and average distillate. Quite recently, and especially in the USA and in Europe, demand for fuel was displaced from gasoline on diesel fuel. It means that while in the past generally easy grades of crude oil were overtaken, today OR have to be capable to overtake heavier grades. The margin of processing went down for many plants which could not adapt to change of a situation. Technological restrictions forced many OR to buy expensive light crude which is not allowing to produce specifically those distillates which are in the greatest demand in the market. For many plants of loss were too big. Many of them were closed or switched from distillation to mixture.

One more not less important task - existence of a large number resinous asphalt of connections, high-melting paraffin and various mechanical impurity as a part of oil extracted in the territory of the Azerbaijan. If temperature of such oil decreases, then paraffin crystallizes and laid on walls of pipelines. Along with other components as a part of emulsion oil it becomes the main reason of decrease in an output of wells. Naturally, further transportation of such product becomes significantly more expensive, and the equipment spoils much quicker. Inhibitors APPD (asphalt pitch of paraffin deposits) help to solve this difficulty. Such substances form on the metal surface of the pipeline a hydrophilic film a high-molecular layer which formation interferes with sedimentation of paraffin, thereby, increasing the general bandwidth of the oil-field equipment. These sulfurcontaining molecules partially decay at distillation while hydrogen sulfide is emitted. Sulfur and other sour components which are contained in crude oil such as naphthenic acids, have high corrosion activity and are responsible for acidity of oil. These characteristics generally determine the price paid for different types of crude oil. Crude oil with a high rate of TAN is characterized by smaller quantity of easy components, high density and viscosity, low temperature of hardening, high content of nitrogen, high content of dense asphalt, high content of salts and heavy metals, and a low exit of light oil distillates. Oil office for it in the desalinating installation is much more difficult, than for usual oil $[1,2]$. These properties also cause poor quality of the products received crude oil and their high corrosion activity. As a rule, crude oil with a high rate of TAN call "accidental crude oil". Its price is about $80 \%$ of the cost of usual crude oil. Additional costs of oil refining with a high rate of TAN are in limits of $1.15-10.73 \$$ /barrel, but economy makes $43.54-62.7 \$ /$ barrel in comparison with processing of usual oil. Thus, use of such oil is very attractive in any possible way to processors. In the past most OR were projected and under construction of materials, according to crude oil, available to them, and ease of its purchase. it limits variability of many oil refineries in purchase of other types of oil, with other qualities [3, 4]. Also special attention needs to be paid to corrosion exposure of the equipment. As the technologically easiest way of protection serves inhibitor use. Inhibitors of corrosion are chemicals which, being present at a system in enough, create the resistant protective layer on a surface of walls of pipelines and other equipment which is slowing down corrosion process. Heavy oil is sour and has bigger corrosion activity, than light crude. Higher viscosity, 
tendency to formation of rainfall and various streams complicate maintenance of stable supply of raw materials which is necessary for a stable exit of products, quality and reliability. Differences in boiling temperatures for light and heavy crude oil demand use of various operating temperatures, such as temperature of preliminary heating, various temperatures of distillation, the top shoulder strap and so on. Heavy types of fuel are rich with asphaltenes and metals and also other pollutants which worsen quality of work of the desalinating installation.

Further researches and the made experiments showed that for improvement of pipeline transport high-paraffinic crude oil application not of one way of improvement of rheological properties of crude oil, and their combination, for example introduction of depressor additive to high-paraffinic oil with its subsequent addition in mix low-viscous crude oil is the most economic. Practice of production, transportation and processing crude oil revealed specificity of influence resinous асфальтеновых components on rheological properties of oil long ago in general. In this case not only viscous properties, but also pronounced influence resinous asphaltens components on emergence of steady emulsions of oil with water mean. Use of depressor additives is represented in the most perspective way of improvement of rheological properties crude oil which high viscosity is caused by high content of paraffin. The main obstacle to broad use of additives is their high cost and also inefficiency in the crude oil with the small content of paraffin which viscosity is caused by high content of asphaltic substances.

\section{EXPERIMENTAL SETUP}

The entity of improvement of rheological properties of oil (ultimate stress of shift, viscosity, thixotropy etc.) consists that it is cooled before formation of paraffinic structure, and then destroy by a mechanical way the last. The pitches and asphaltenes which are contained in oil envelop splinters of paraffinic structure, interfering with their repeated connection. The paraffin suspension received thus in oil rather progressive tense saves necessary mobility at normal speeds of transfer [5]. Studying of this process and influence of chemical reagents on rheological properties of oil is also of interest when developing tertiary methods of oil production with use of the special chemical reagents capable to interact with metalporphyrines. Thus, the existing recommendation about technologies of mixing should add with the criteria taking into account interference as a part of separate components allowing to make necessary assessment of "unacceptable" and also "optimum" concentration of asphaltenes and other high-molecular chemical compounds in oil mixtures [6]. The analysis of composition of high-viscosity oils shows that though their density is close, rheological and physical and chemical properties considerably differ from each other. Looking at physical and chemical characteristics of the high density and bituminous oils extracted on oil fields in Azerbaijan, Russia and the USA, apparently, that they completely differ from each other (Table 1).

Table 1. Properties of some high-viscosity oils of Azerbaijan, Russian Federation and Canada.

\begin{tabular}{|c|c|c|c|c|c|}
\hline Results & Mordov-Karmal & Ashalcin & $\begin{array}{l}\text { Suqu- } \\
\text { shlin }\end{array}$ & Atabaska & Murad-khanl \\
\hline Density, $\mathrm{kg} / \mathrm{m}^{3}$ & $952-970$ & $960-965$ & 980 & 1014 & 878 \\
\hline Viscosity, $\mathrm{mPa} \cdot \mathrm{s}$ & $\begin{array}{c}2500-3000 \\
\left(7-9{ }^{\circ} \mathrm{C}\right) \\
\end{array}$ & $\begin{array}{c}6000-17000 \\
\left(7-9^{\circ} \mathrm{C}\right)\end{array}$ & $\begin{array}{c}2 \cdot 10^{6} \\
\left(7-9{ }^{\circ} \mathrm{C}\right) \\
\end{array}$ & $\begin{array}{l}(1-5) \cdot 10^{6} \\
\left(5-6^{\circ} \mathrm{C}\right) \\
\end{array}$ & $\begin{array}{c}2100-2400 \\
\left(7-9^{0} \mathrm{C}\right) \\
\end{array}$ \\
\hline $\begin{array}{l}\text { Group comp. } \\
\% \text { - mass. } \\
\text { Asphaltenes } \\
\text { Resin } \\
\text { Oils }\end{array}$ & $\begin{array}{c}4.78-7.6 \\
18.3-23.3 \\
4 \\
\end{array}$ & $\begin{array}{c}6.4-8.7 \\
20.1-38 \\
53-73 \\
\end{array}$ & $\begin{array}{l}14 \\
33 \\
54\end{array}$ & $\begin{array}{c}16.1 \\
39 \\
21\end{array}$ & $\begin{array}{c}4.8 \\
12.7 \\
3.6\end{array}$ \\
\hline $\begin{array}{c}\text { Quantity of paraffin, } \\
\% \text { - mass. }\end{array}$ & 1.12 & Min. 0.5 & - & - & 9.6 \\
\hline $\begin{array}{c}\text { Element } \\
\text { composition, } \\
\% \text { - mass. } \\
\mathrm{C} \\
\mathrm{H} \\
\mathrm{S} \\
\mathrm{N} \\
\mathrm{O}\end{array}$ & $\begin{array}{c}83.2 \\
11.0 \\
4.7 \\
0.3 \\
0.8\end{array}$ & $\begin{array}{c}80.8-81.9 \\
10.5-11.2 \\
3.2-4.6 \\
0.4-0.5 \\
3.3-3.6\end{array}$ & $\begin{array}{c}82.7 \\
10.2 \\
4.7 \\
0.4 \\
2.0\end{array}$ & $\begin{array}{c}83.1 \\
10.1 \\
4.8 \\
0.4 \\
1.1\end{array}$ & $\begin{array}{c}84.1 \\
11.8 \\
3.5 \\
0.2 \\
0.4\end{array}$ \\
\hline
\end{tabular}

Insufficient study of processes of interaction of hydrocarbons of oil with various chemical reagents and also lack of methods of establishment of regularities of interaction of components of the bedded environment depending on structure, properties to the conditions of application of chemical reagents complicate the solution of a task of 
determination of prospects of chemicals for oil production. The results show that it would not be right to classify oils from concentration in terms of density, viscosity, and sulfur in terms of the chemical composition of the oil, which should be studied in a wider range [7].

Recently, the most effective outcome for improving the rheological properties of oils has been achieved by the addition of chemical reagents [8]. The most widely spread of these are high-molecular compounds of different types: copolymers of vinyl acetate copolymers, copolymers of ether, which are formed by unsaturated acids (acrylic or methacryl), oxygenous fragments of functional substituent quinine compounds (polyoxyethyl and complex ether groups) and others. For example, these chemical reagents can be used to regulate the rheological properties of oil and cause unavoidable adverse events in the production. Thus, such reagents have little or no effect on the improvement of the rheological properties of high-density, resin-asphaltenic oils [9]. Therefore, the production and use of new type reagents is still needed to regulate the rheological properties of oil. Such approvals are the subject of theoretical discussion, and have not been justified in production. R-140, GY-3, DANOX-501, DNN-2005, CCP, AR-174 are used to regulate the rheological properties of oil extraction and storage in several countries. The most effective reagents for these oils from the CIS countries are the chemical reagents of the RK. The composition of this reagent is mainly made up of solvents (native oils and oils) and compositions (a mixture of synthetic depressor additives mixture with native oils). This reagent is considered to be economically ineffective due to unwanted conditions in oil mixing when used in oil transportation.

\section{RESULTS AND DISCUSSION}

The effect of the SNPX-2005 additive on the improvement of the realogue of oil from the resin, asphaltenes, was of great interest [10-12]. For this, the kinematic viscosity of Muradkhanli and Sangacal crude oils was checked in the reduced ratio of SNPX-2005 additive. The results of the inspection showed that the added value added to the oil, the price of the cinematic extract of oil, was considerably greater than the price it had received before it was added. Given that oil has a high viscosity, it has been investigated dynamically with their Ratase style.

To measure influence of oil samples on dynamics of their viscosity, SNPX-2005 was added to Muradkhanli and Sangacal crude oils of $0.8 \mathrm{~kg} / \mathrm{t}$. Measurements were measured in $5,10,20^{\circ} \mathrm{C}$ temperatures and at change of the coping stages $\left(1-12,0.333 ; 0.6 ; 1 ; 1.8 ; 3 ; 5.4 ; 9 ; 16.2 ; 27 ; 48.6 ; 81 ; 145.8\right.$ seconds $^{-1}$ are compatible to a gradient). The sum of SNPX-2005 which is let out in oils was reduced up to $1.0 \mathrm{~kg} / \mathrm{t}$, and new measurements in $5{ }^{\circ} \mathrm{C}$ were executed. Dynamics of dynamic viscosity at various stages, reflecting Muradkhanli and Sangacal crude oils in 20,10 and $5{ }^{\circ} \mathrm{C}$ and addition of a dose of SNPX-2005 0.8, $1.0 \mathrm{~kg} / \mathrm{t}$ is reflected in the Figure 1-12.

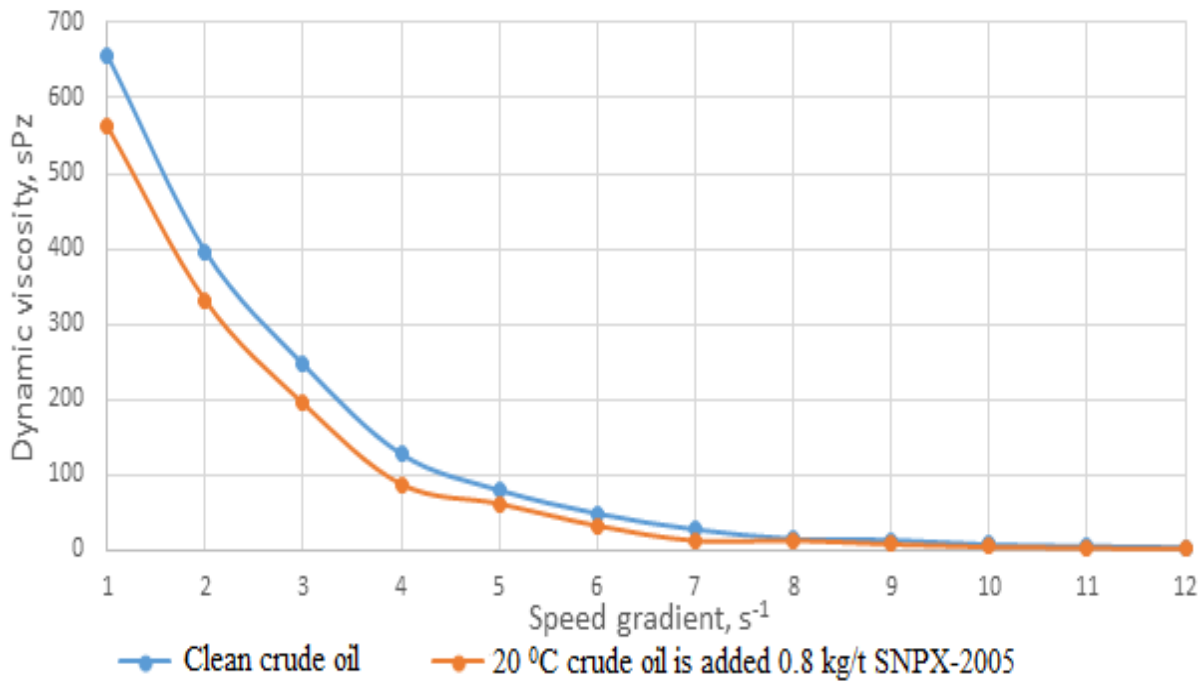

Fig. $1.20^{\circ} \mathrm{C}$ Muradkhanli crude oil is added $0.8 \mathrm{~kg} / \mathrm{t} \mathrm{SNPX-2005.}$

The main technological parameters that control the process efficiency are: the discharge current, the distance between the electrodes, the pressure and nature of the working gas, the electrodes composition, shape and 
dimensions. Our analysis shows that the SNPX-2005 has a different ability to affect the realm of Muradkhanli oil. Muradkhanli oil has a different effect on the mixed oils generated by mixing in different proportions. As can be seen from the photographs, the additive of $0.8 \mathrm{~kg} / \mathrm{t}$ has a mean decline of $20{ }^{\circ} \mathrm{C}$ at $19.3 \%, 10{ }^{\circ} \mathrm{C}$ at $26.1 \%$ and $5{ }^{0} \mathrm{C}$ for $10.1 \%$. This shows that at low temperatures, the effect of the additive on the stream decreases at all speeds, increasing the content of the additive to $5{ }^{\circ} \mathrm{C}$ by increasing the amount of additive to $1.0 \mathrm{~kg} / \mathrm{t}$. Along with physical and chemical properties of mix, the software has to be focused also on the possible profit got from mixture. It demands that the software also included: Cost various crude oil and their mixes, price of final distillates and other products of oil processing. Separate tanks, load into the mixing tank where they mix up before obtaining homogeneous structure. Contents of tanks mechanically mix up. It is necessary to select tests for definition whether mix is uniform and whether it meets its predetermined specification. In case of not compliance mix correction has to be made. All procedure of mixture in tanks is very labor-consuming and expensive. Unlike mixture in the tank, line mixture is carried out by simultaneous giving of different types of crude oil in the tank of final mix by means of the static line mixing device. Effectively and unmistakably to operate mixture process, line analyzers are necessary. The set ratio of streams at various gives to nefty mix of the required quality. Line mixture allows to adjust in line quality of mix by change of a ratio of the given raw materials. Mix is produced instantly, and there is no need to mix it in mixture tanks.

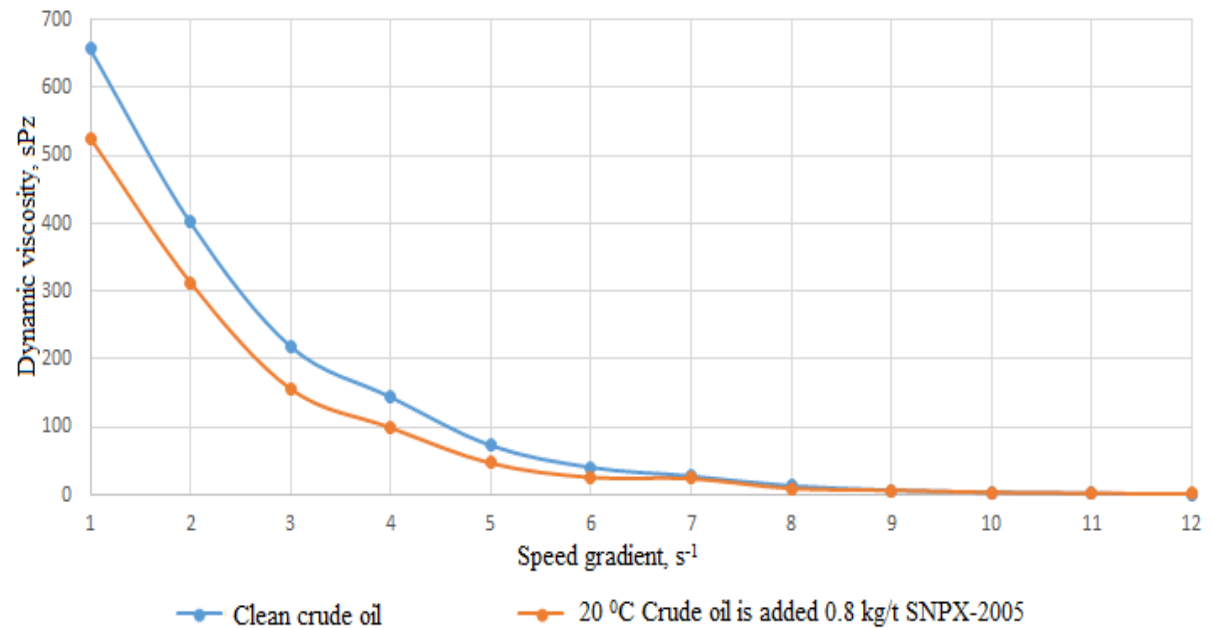

Fig. $2.20^{\circ} \mathrm{C}$ Sangacal crude oil is added $0.8 \mathrm{~kg} / \mathrm{t} \mathrm{SNPX}-2005$.

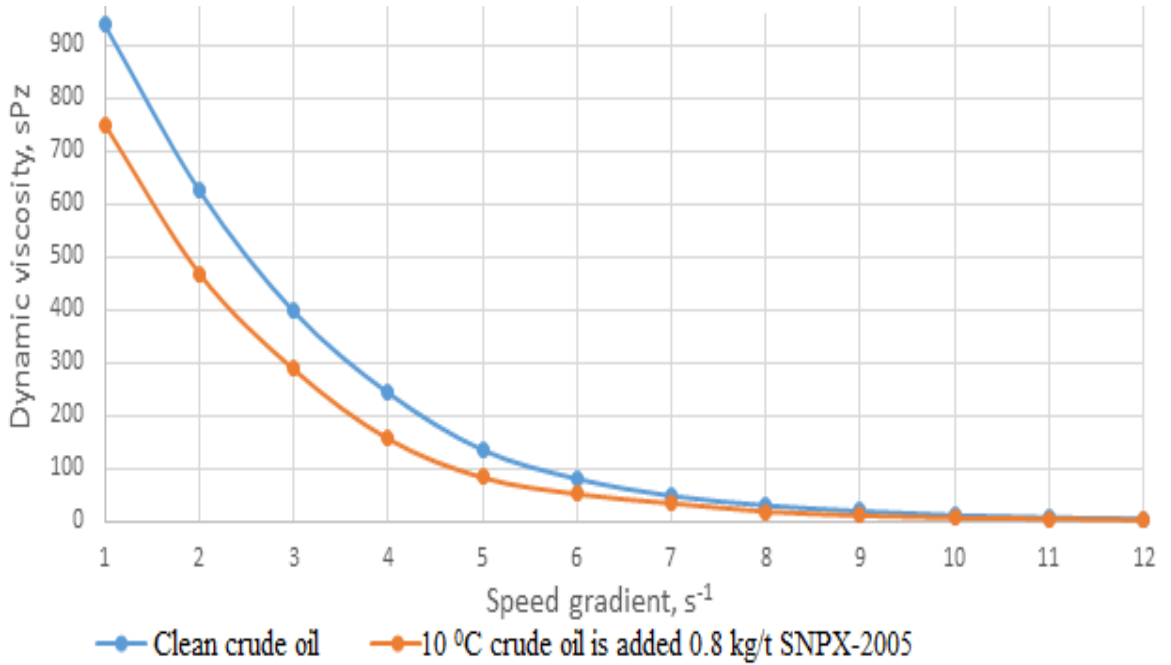

Fig. 3. $10^{\circ} \mathrm{C}$ Muradkhanli crude oil is added $0.8 \mathrm{~kg} / \mathrm{t} \mathrm{SNPX-2005.}$ 


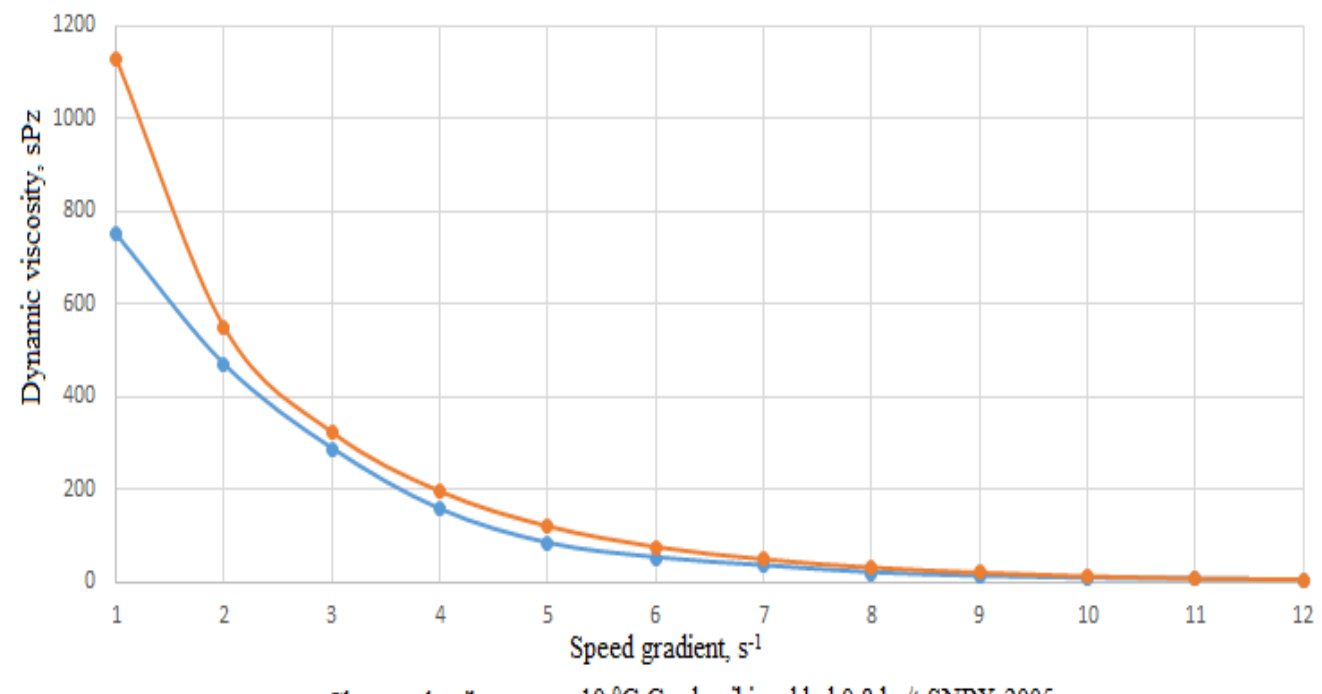

Fig. $4.10^{\circ} \mathrm{C}$ Sangacal Crude oil is added $0.8 \mathrm{~kg} / \mathrm{t}$ SNPX-2005.

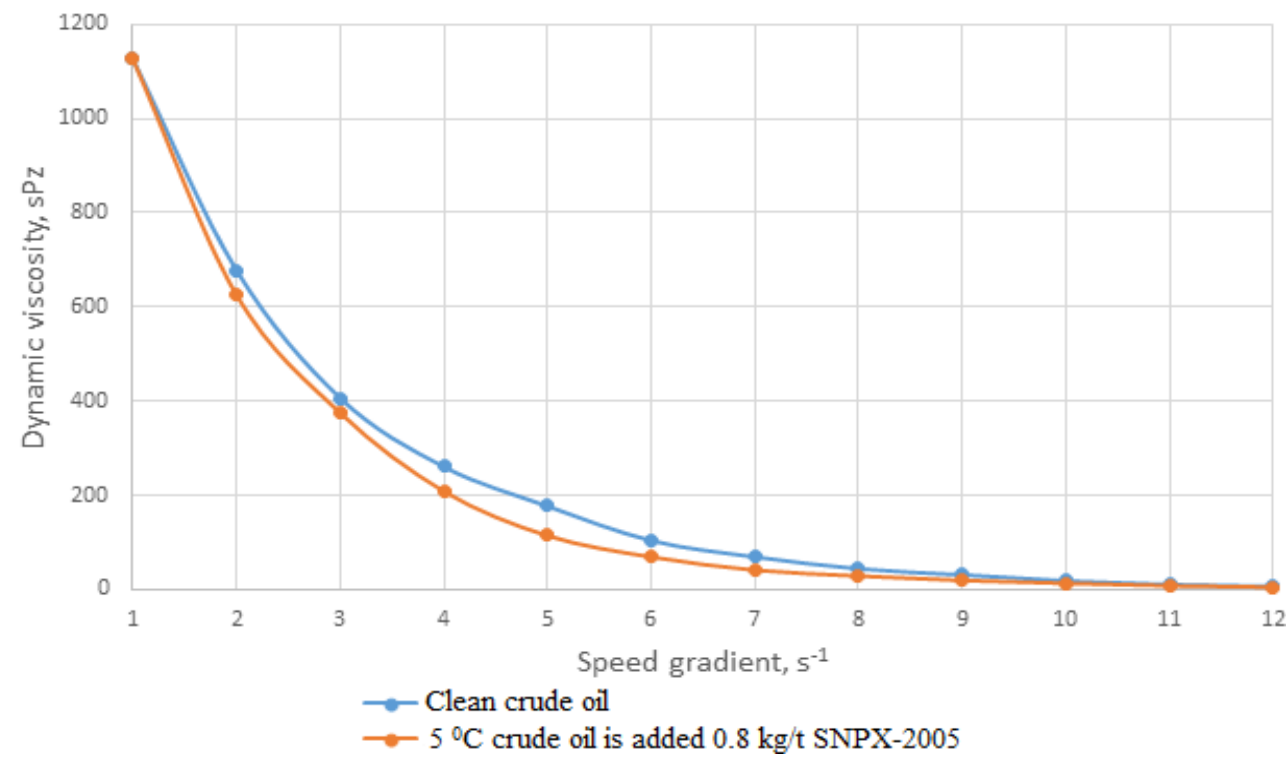

Fig. $5.5^{0} \mathrm{C}$ Muradkhanli crude oil is added $0.8 \mathrm{~kg} / \mathrm{t}$ SNPX-2005. 


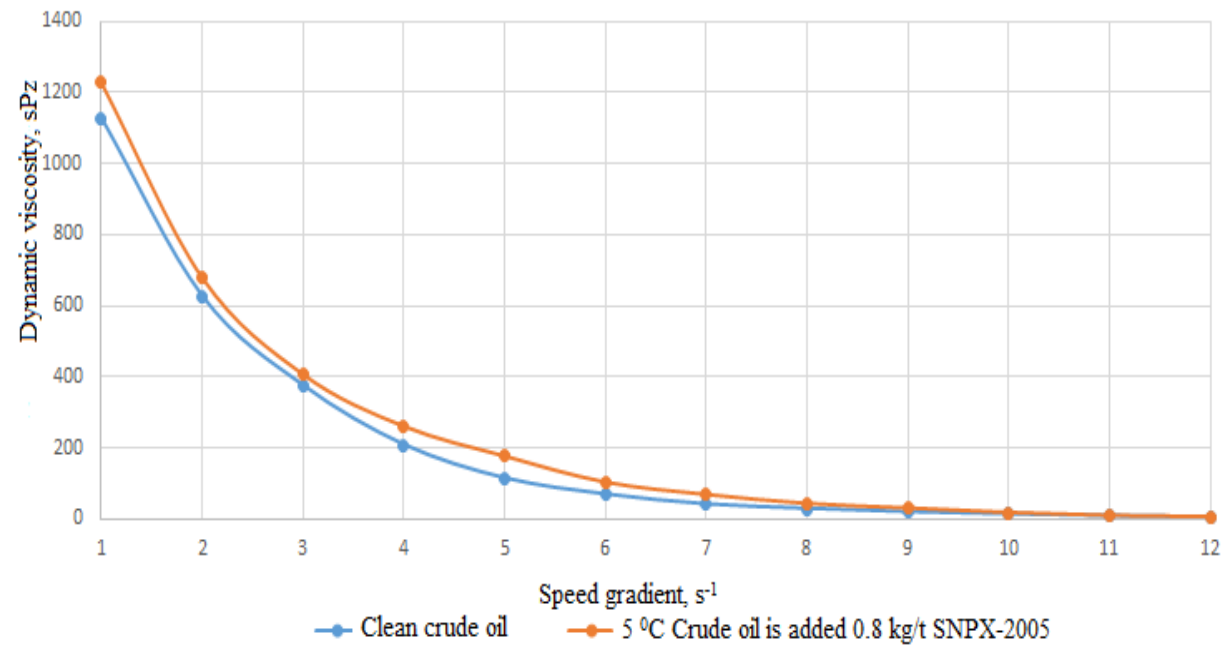

Fig. $6.5^{0} \mathrm{C}$ Sangacal crude oil is added $0.8 \mathrm{~kg} / \mathrm{t}$ SNPX-2005.

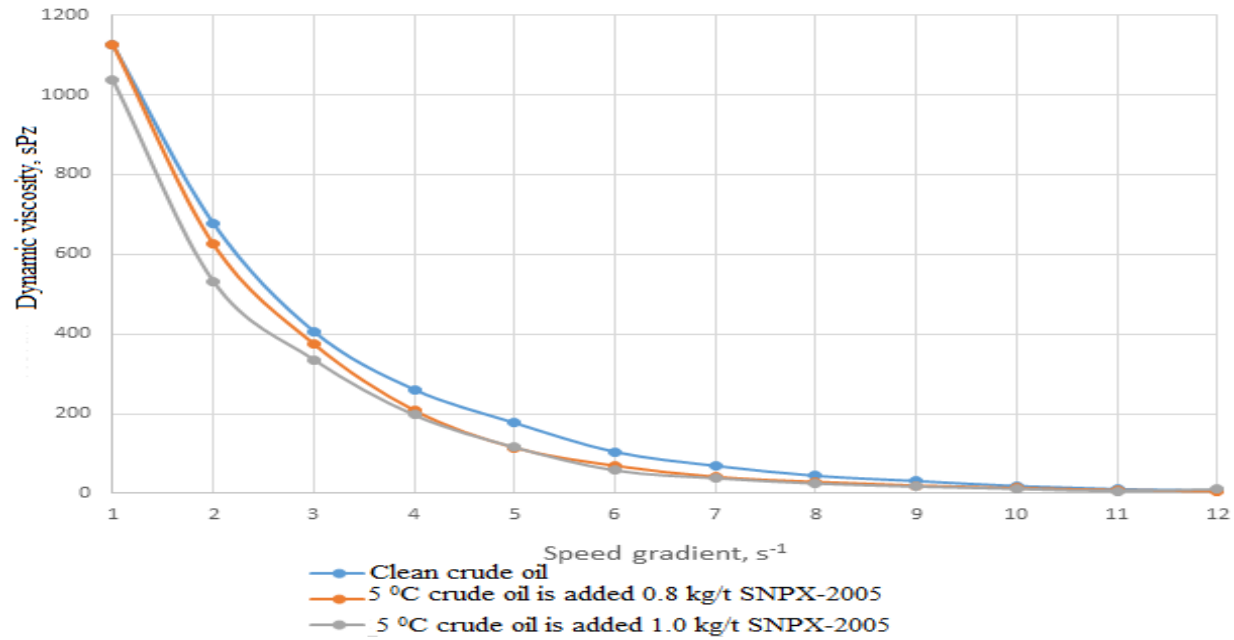

Fig. 7. $5^{0} \mathrm{C}$ Muradkhanli crude oil is added 0.8, $1.0 \mathrm{~kg} / \mathrm{t} \mathrm{SNPX-2005.}$

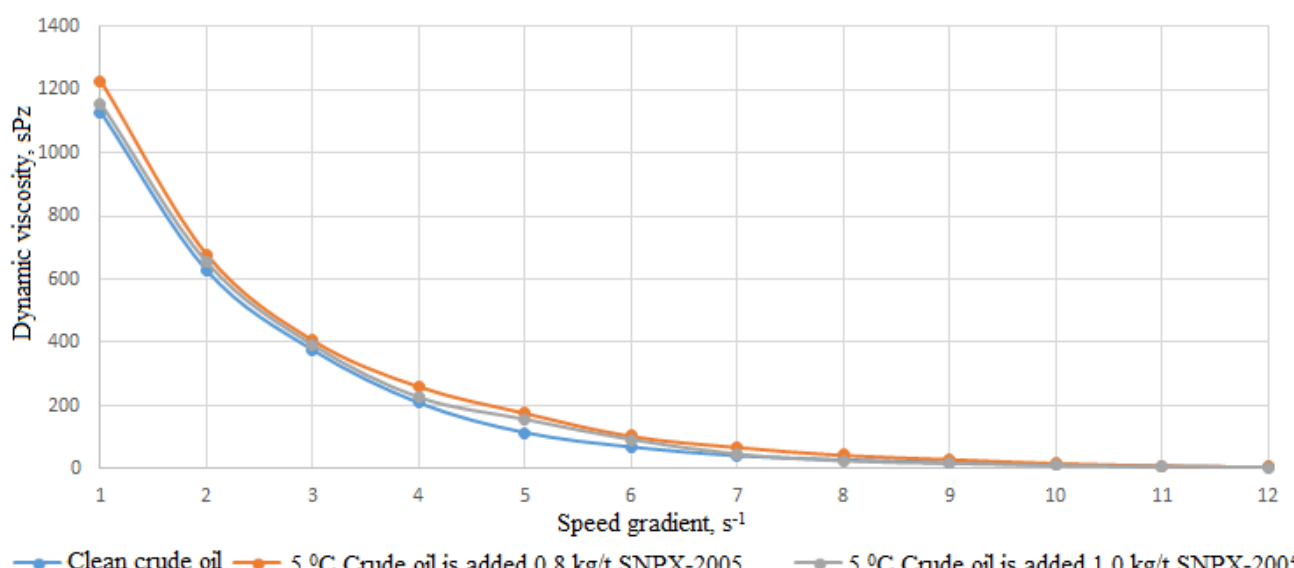

Fig. $8.5^{0} \mathrm{C}$ Sangacal crude oil is added $0.8,1.0 \mathrm{~kg} / \mathrm{t} \mathrm{SNPX-2005.}$ 


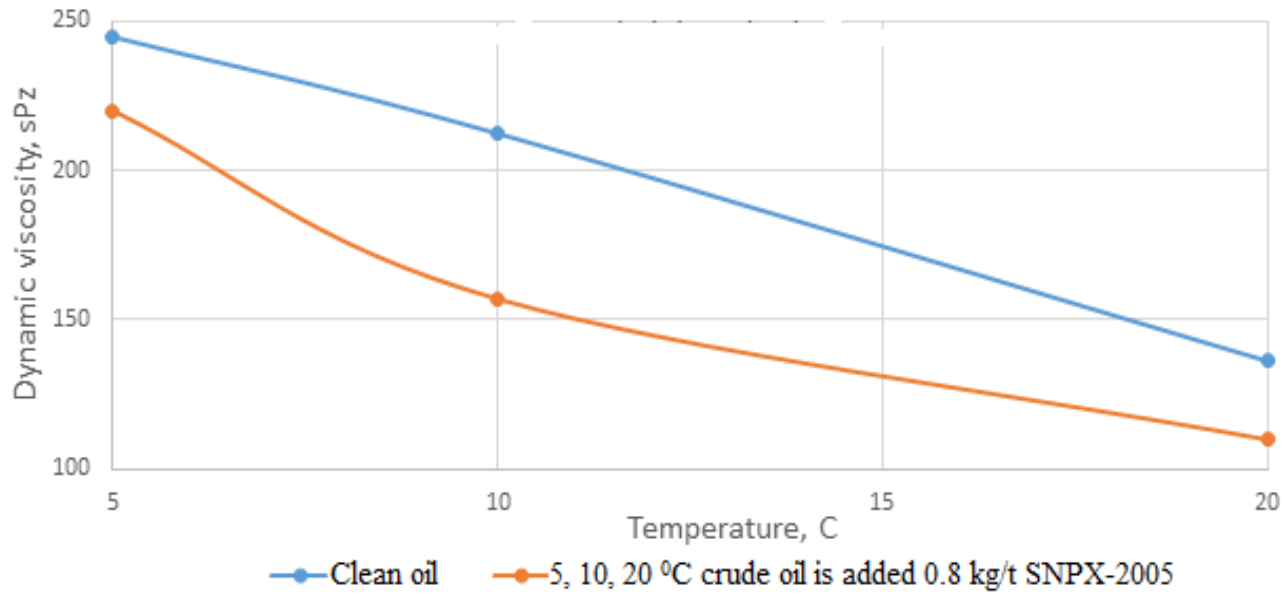

Fig. 9. 5, 10, $20^{\circ} \mathrm{C}$ Muradkhanli crude oil is added $0.8 \mathrm{~kg} / \mathrm{t} \mathrm{SNPX-2005.}$

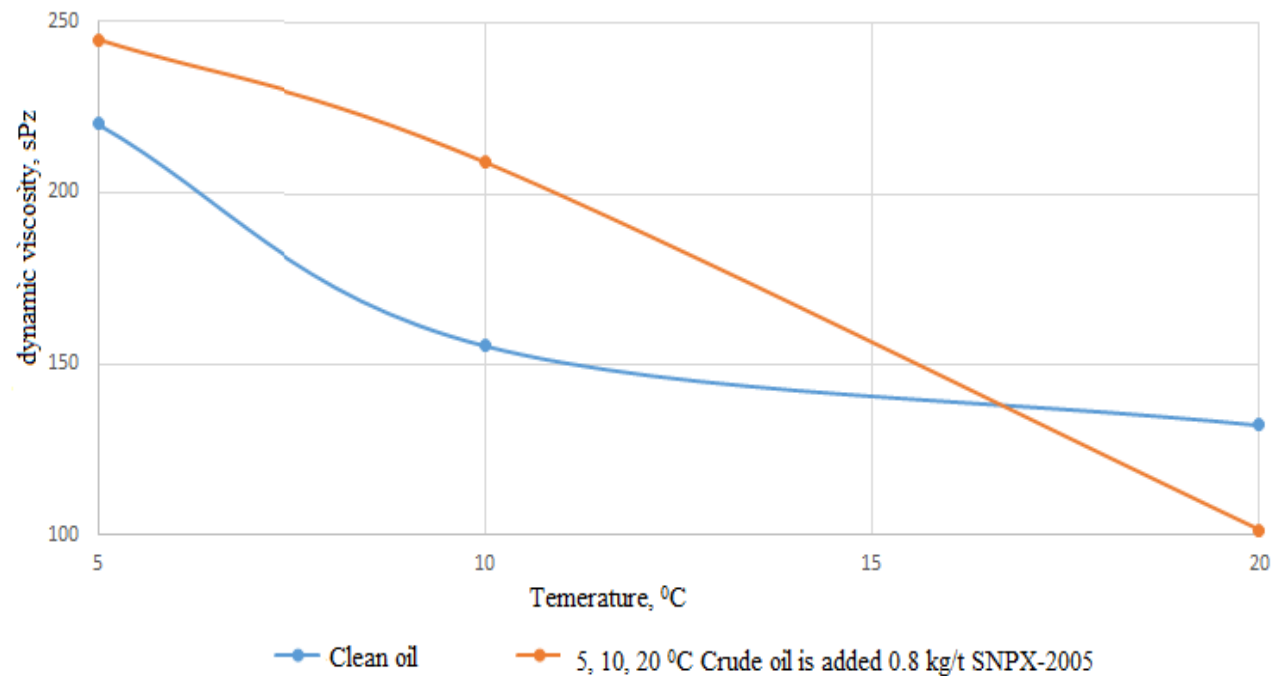

Fig. 10. 5, 10, $20^{\circ} \mathrm{C}$ Sangacal crude oil is added $0.8 \mathrm{~kg} / \mathrm{t}$ SNPX-2005.

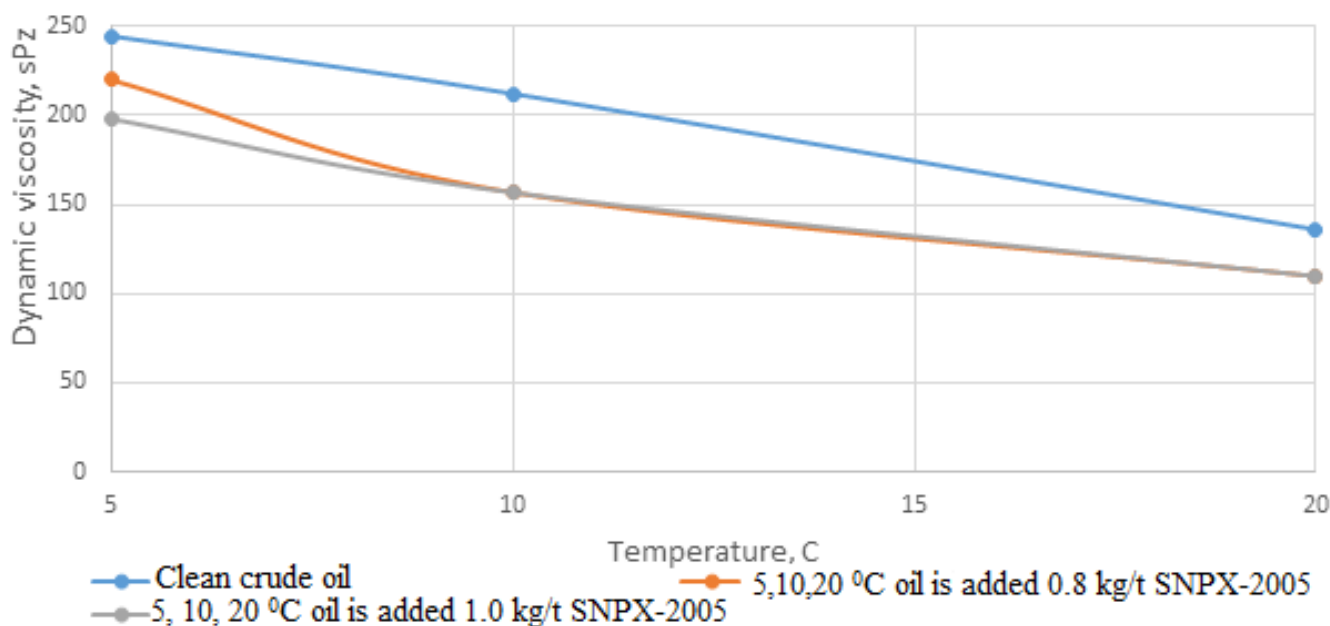

$=-5,10,20^{\circ} \mathrm{C}$ oil is added $1.0 \mathrm{~kg} / \mathrm{t} \mathrm{SNPX}-2005$

Fig. 11. 5, 10, $20^{\circ} \mathrm{C}$ Muradkhanli crude oil is added 0.8 and $1.0 \mathrm{~kg} / \mathrm{t}$ SNPX-2005. 


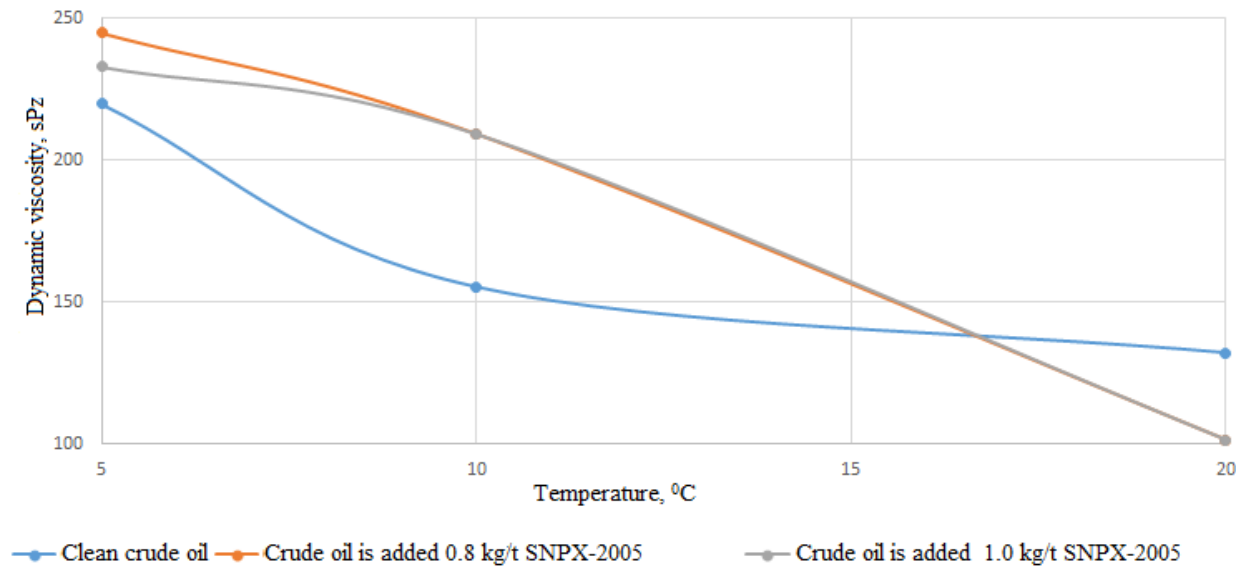

Fig. $12.5,10,20^{\circ} \mathrm{C}$ Sangacal crude oil is added 0.8 and $1.0 \mathrm{~kg} / \mathrm{t} \mathrm{SNPX-2005.}$

Effectively and unmistakably to operate mixture process, line analyzers that instantly are necessary to measure mix parameters at the exit and to provide to operators of mixture necessary information on qualitative parameters of the received mix. It allows to adjust mix in real time on a stream in mixture process, providing mix with predetermined properties. It excludes the adjusting repeated mixture in volume the whole tank and also reduces an exit of unnecessary sub-standard products.

Research and the choice of chemical reagents are carried out generally by practical consideration. More expedient is the integrated approach based on physical and chemical researches of characteristics of the main properties of chemical reagents and their changes under the influence of geological and technology factors of the bedded environment with various modern tool methods, laboratory and trade researches. In the conditions of concrete oil fields it is necessary that the chemicals which are picked up by practical consideration and their compositions had the following complex of physical and chemical properties.

They have to be dissolved in water and organic compounds to lower a superficial tension on limit of the section of phases and to improve wettability of breed water to have the high petrowashing and forcing-out properties to improve rheological properties of oil to prevent or not to cause adjournment of asphaltic and paraffin substances in the porous environment and the well not to promote in interaction with clay to its swelling not to stimulate formation of water oil emulsions.

\section{CONCLUSIONS}

Given that, in reality, most solid bodies and liquids, especially oil and petroleum products, behave like galoid systems, rheological physico-chemical science helps explain the causes of changes and changes in mechanical effects in dispersed systems and high molecular compounds. At application of a complex method of introduction of reagent to the system of the pipeline the viscosity of oil considerably decreases in comparison with a usual method.

The specified reagents can be applicable for reduction of viscosity of oil products, such as heavy oil and crude oil, for the purpose of simplification of transportation from underground layer or between the place of production and oil refinery or oil storage. Application of the specified emulsions increases oil production and is a costeffective alternative to heating of pipelines or to use of thinners for transportation of heavy crude oil. The given results of preliminary experiments show that specified reagents can be used for clarification crude oil and oil products from slimes in tanks.

\section{ACKNOWLEDGEMENT}

The authors gratefully acknowledge the research council of State Oil Company of the Azerbaijan Republic and Geotechnological Problems of Oil, Gas and Chemistry Scientific Research Institute, within Azerbaijan State Oil and Industry University. 


\section{REFERENCES}

[1] Mansoori, G.A., Paraffin/wax and waxy crude oil. The role of temperature on heavy organics deposition from petroleum fluids. Available at: URL: http://www.uic.Edu/mansoori/WaxandWaxy.Crude_html (6.03.2019).

[2] Gilby, G.W., Use of ethylene-vinyl acetate copolymers as flow improvers and wax deposition inhibitors in waxy crude oil, Chemical Oil and Process Symposium, 1998, p. 143-152.

[3] Mastobaev, B.N., Khaibullin, R.Ya., The impact of asphaltene substances on the process of oil product pipelines waxing, Transport and storage of petroleum products and hydrocarbons, no. 8, 1981, p. 9-10.

[4] Mirzadzhanzade, A.Kh., Gallyamov, A.K., Maron, V.I., Yufin, V.A., Hydrodynamics of pipeline transportation of oil and oil products, Moscow, Nedra, 1984.

[5] Nadirov, N.K., Tugunov, P.I., Pipeline transportation of viscous oils ser, New crude oil of Kazakhstan and its application, Alma-ata, Nauka, 1985.

[6] Ismailov, G.G., Nurullaev, V.Kh., Kelova, I.N., Nurmamedova, R.G., The effect of mixing oils different in their rheological and physicochemical properties, Proceedings of the Fifth International Scientific and Practical Conference, Problems of Innovative Development of the Oil and Gas Industry, February, 21-22, Almata, KBTU, 2013, p. 21-27.

[7] Ismailov, G.G., Kuliev, M.M., Nurullaev, V.Kh., Keleova, I.N., Guliev, V.K., Accounting the structural stability of abnormal flows in oil gathering systems network, no. 4, 2010, p. 31-33.

[8] Nebogina, N.A., Prozorova, I.V., Yudina, N.V., Influence of the Water content in the oil formation and rheological properties of water-oil emulsions, Oil industry, no. 12, 2008, p. 90-92.

[9] Sazhin, V.V., Seldinas, I., Sazhin, V.B., Hard to recover reserves and heavy oil of Russia, Progress in Chemistry and Chemical Technology, 2008, vol. 92, no. 12 , p. 56-68.

[10] Yevdokimov, I.N., Yeliseev, D.Yu., Yeliseev, N.Yu., A negative anomaly of viscosity of liquid petroleum products after heat treatment, Chemistry and Technology of Fuels and Oils, no. 3, 2002, p. 26-29.

[11] Zhuiko, P.V., Development of principles of control of abnormal rheological properties of oils, Ukhta, UGTU, 2003.

[12] Usubaliev, B.T., Ramazanova, E.E., Murvatov, F.T., Application of coordination polymers to increase the reservoir oil recovery, Science and Applied Engineering, no. 6, 2015, p. 16-21. 